\title{
Evaluation of the efficiency of antibiotic prophylaxis in cesarean cases
}

\author{
Reyhan Kaplan Hafızoğlu, ${ }^{1}$ Serkan Kumbasar, ${ }^{1}$ Bulat Aytek Şık, ${ }^{2}$ Murat Bozkurt, ${ }^{1}$ \\ Mustafa Ulaş, ${ }^{3}$ Ayse Ender Yumru, ${ }^{4}$ Burcu Dinçgez, ${ }^{5}$ Süleyman Salman ${ }^{6}$
}

Keywords: Antibiotic prophylaxis, infection, cesarean section

\begin{abstract}
Background: In recent years the rate of cesarean section has significantly increased.To determine the efficacy of prophylactic antibiotics in reducing infectious morbidity after cesarean section.

Objectives: In our study, we aimed to evaluate the efficiency of prophylactic antibiotic administration by comparing three groups using single, multiple and no prophylactic antibiotic therapy.

Materials and Methods: Our study is a prospective, randomized controlled study including emergent cases, that developed cesarean indication while in active labor, and elective cesarean cases. A total of 90 patients were included in the study, including 30 patients who underwent cesarean delivery and did not undergo an antibiotic prophylaxis (Group 1), 30 patients who underwent a single dose antibiotic prophylaxis (Group II) and 30 patients who underwent multiple dose antibiotic prophylaxis (Group III).
\end{abstract}

Results: The incidence of wound infection was significantly higher in cases that were not using

Please cite this paper as: Hafızoğlu RK, Kumbasar S, Şık BA, Bozkurt M, Ulaş M, Yumru AE, Dinçgez B, Salman S. Evaluation of the efficiency of antibiotic prophylaxis in cesarean cases. Proc Obstet Gynecol. 2016;6(1): Article 1 [ 10 p.]. Available from: http://ir.uiowa.edu/pog/ Free full text article.

Corresponding author: Murat Bozkurt, Assistant Professor, Department of Obstetrics and Gynecology, Sakarya University School of Medicine, Sakarya Research and Education Hospital, Sakarya, Turkey, Email: iindrmb@yahoo.com

Financial Disclosure: The authors report no conflict of interest.

Received: 21 October 2015; accepted 1 February 2016; POG in Press, 9 March 2016

Copyright: (c) 2016 Hafızoğlu et al. This is an open-access article distributed under the terms of the Creative Commons Attribution License, which permits unrestricted use, distribution, and reproduction in any medium, provided the original author and source are credited. 


\section{Background}

Infection risk is significantly increased in women who undergo cesarean delivery compared to those who deliver vaginally. Infection rates following cesarean section vary between $7 \%$ and $20 \%$ due to demographic and obstetric factors. ${ }^{1,2}$ Therefore, the most significant risk factor for postpartum maternal infection is cesarean delivery. ${ }^{3}$ Hospitalization time increases due to the complications associated with infection following cesarean. ${ }^{4}$

Complications associated with infections following cesarean delivery are fever, wound infections, endometritis, bacteriemia, pelvic abscess, septic shock, necrotizing fascitis, septic pelvic vein thrombophlebitis and urinary system infections. ${ }^{2,5,6}$ Endometritis and wound infections are still the most significant causes of postoperative infectious morbidity. ${ }^{4}$ While the incidence of endometritis is between 20\%-85\% without antibiotic prophylaxis, severe complication rates associated with wound infection and infections are reported as $25 \%{ }^{7}$

The administration of prophylactic antibiotics decreases the incidence of infectious morbidity following cesarean by a rate of $75 \%$ in both planned and emergent caesarean deliveries. ${ }^{8,9,10}$

First generation cephalosporins are the most commonly used antibiotics in prophylaxis, generally being administered after clamping the cord of the newborn. ${ }^{11}$ Antibiotics are given before skin incision in most of the surgical operations requiring prophylaxis. ${ }^{12}$

Sullivan and Thigpen have found that preoperative antibiotic prophylaxis decreased the incidence of infectious morbidity compared to prophylaxis administration after cord clamping. ${ }^{13,14}$ Fejgin et al. also found that the incidence of wound infections was low in the group which was given preoperative antibiotic prophylaxis. ${ }^{15}$ Wax et al. have reported that administration of prophylaxis before the operation or after cord clamping does not affect infectious morbidity. ${ }^{16}$

\section{Objectives}

In this study, we aimed to evaluate the efficiency of prophylactic antibiotic administration by comparing groups that were administered single dose and multiple doses along with those who were not administered prophylactic antibiotic therapy.

\section{Materials and Methods}

Our study is a prospective, randomized controlled study including emergent cases, who developed cesarean indications while in active labor, and cases of elective cesarean. A total of 90 patients were included in the study, including 30 patients who underwent cesarean delivery and did not undergo antibiotic prophylaxis (Group 1), 30 patients who underwent a single dose antibiotic prophylaxis (Group II) and 30 patients who underwent multiple dose antibiotic prophylaxis (Group III). Patients included were at 34-41st gestational weeks. Patients were excluded for the following reasons early membrane rupture, chorioamnionitis, vaginal bleeding, diabetes, maternal obesity, allergies to penicillin and cephalosporin and signs of infection. All patients were enrolled in the study after being informed about the aim and 
possible results of the study and treatment protocols, and after giving informed consent. A catheter was inserted into the bladder before cesarean in all cases. The skin was cleaned with povidone iodine before the operation. All cases underwent cesarean delivery under general anesthesia. The study was approved by the ethics committee of the hospital.

$1 \mathrm{~g}$ Cephazoline Sodium (Sefazol 1g flk,(Mustafa Nevzat) was used for antibiotic prophylaxis during cesarean delivery. $1 \mathrm{~g}$ Cephazoline Sodium was mixed with $50 \mathrm{cc}$ normal saline, and it was administered to the patients in Group II as a single dose at least 10 minutes before skin incision and to the patients in Group III as three doses including at least 10 minutes before skin incision and at 12 and 24 hours following skin incision. Antibiotic prophylaxis was not given to the patients in Group I.

Complete blood count and C-reactive protein (CRP) were measured during the preoperative period. Patients were evaluated for axillary fever and an increase in vaginal temperature. Complete blood count and CRP were measured on the first day postoperative. Patients were evaluated for axillary fever, presence of purulent lochia, tachycardia and an increase in vaginal temperature. On postoperative days 3,5 and 7 , they were evaluated for the presence of purulent lochia, tachycardia, an increase in vaginal temperature, redness on the incision line, sensitivity, edema, local temperature increase and discharge.

Diagnosis of febrile morbidity was defined as fever that is above $37.5^{\circ} \mathrm{C}$ after postoperative 24th hours at 4 -hour intervals. Increased uterine sensitivity and/or presence of malodorous or purulent lochia was accepted as endometritis. Diagnosis of wound infection was made in the presence of discharge, stiffness, erythema and edema on the incision site. Infection was not considered in the presence of hematoma, seroma and wound opening.

Empirical antibiotherapy was started after taking necessary cultures from the patients with postoperative infection. Re-treatment was arranged for the patients who did not respond to empirical treatment based on culture results. Cases were followed up for signs of infection during hospitalization. They were verbally informed to watch for signs of infection before discharge from the hospital and examined again at the second and fourth weeks following delivery.

\section{Statistical Analysis}

Results obtained from the study were evaluated, using the NCSS (Number Cruncher Statistical System) 2009 \& PASS 2009 Statistical Software (Utah, USA) program for statistical analysis. In addition to descriptive statistical methods (mean, standard deviation, frequency), one way Anova test was used in intergroup comparisons of the parameters showing normal distribution, and Tukey HSD test was used for the detection of the group leading to the difference. Chi-Square test was used in intergroup comparisons of qualitative data and statistical significance was evaluated at $p<0.05$ level.

\section{Results}

The study included 90 women, between the ages of 18 and 35 years, at the 
Ministry of Health Okmeydani Training and Research Hospital Maternity Clinic, between 1 June 2009 and 1 October 2009. The mean age of the patients was 28.04 \pm 4.18 years. Patients were assigned to three groups each containing 30 cases based on their prophylaxis use, including "Single Use", "Multiple Use" and "No Antibiotics use". Hospitalization time of the cases varied from 3 to 5 days and mean hospitalization was $3.20 \pm 0.60$ days.

The mean body mass index of the cases was 76.51 \pm 7.92 . The gestational weeks of the cases were between 31 and 42 weeks with the mean being $38.26 \pm 1.71$ weeks. The number of gravida among the cases varied from 1 to 8 with a median of 2 . The number of parities was between 0 and 5 with a median of 1 . The number of abortions was between 0 and 4 with a median of 0 while the number of curettages varied between 0 and 2 and the median was 0 . Preoperative hemoglobin levels varied from 8.3 to 14.9 , with a mean of

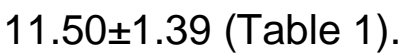

Table 1: Demographic data

\begin{tabular}{|l|c|}
\hline & $\begin{array}{c}\text { Mean } \pm \text { SD } \\
(\text { Median) }\end{array}$ \\
\hline Weight & $76.51 \pm 7.92$ \\
\hline Gestational week & $38.26 \pm 1.71$ \\
\hline Gravida & $2.23 \pm 1.23(2)$ \\
\hline Parity & $0.84 \pm 0.86(1)$ \\
\hline Abortion & $0.29 \pm 0.67(0)$ \\
\hline Curettage & $0.67 \pm 0.33(0)$ \\
\hline Preop Hemoglobin & $11.50 \pm 1.39$ \\
\hline
\end{tabular}

The distribution of cesarean indications within each group and the total is given in Table 2. Among all cases, a previous cesarean section (C/S) was observed in $44.4 \%$, fetal distress in $16.7 \%$, preeclampsia in $10 \%$, cephalopelvic disproportion (CPD) in 8.9\%, obstructed labor in $6.7 \%$, breech in $5.6 \%$, placenta previa in $4.4 \%$, maternal factor in $2.2 \%$ and twin pregnancy in one case.

Table 2: Distribution of cesarean indications

\begin{tabular}{|l|c|c|c|c|}
\hline C/S Indications & $\begin{array}{c}\text { Single } \\
\text { antibiotics use }\end{array}$ & $\begin{array}{c}\text { Multiple } \\
\text { antibiotics use }\end{array}$ & No antibiotics & Total \\
\hline Previous C/S & $\mathrm{n}(\%)$ & $\mathrm{n}(\%)$ & $\mathrm{n}(\%)$ & $\mathrm{n}(\%)$ \\
\hline Preeclampsia & $17(56.7 \%)$ & $10(33.3 \%)$ & $13(43.3 \%)$ & $40(44.4 \%)$ \\
\hline Fetal Distress & $3(10.0 \%)$ & $5(16.7 \%)$ & $1(3.3 \%)$ & $9(10.0 \%)$ \\
\hline CPD & $7(23.3 \%)$ & $3(10.0 \%)$ & $5(16.7 \%)$ & $15(16.7 \%)$ \\
\hline Placenta Previa & $1(3.3 \%)$ & $3(10.0 \%)$ & $4(13.3 \%)$ & $8(8.9 \%)$ \\
\hline Obstructed labor & $0(0 \%)$ & $4(13.3 \%)$ & $0(0 \%)$ & $4(4.4 \%)$ \\
\hline Maternal Factor & $1(3.3 \%)$ & $2(6.7 \%)$ & $3(10.0 \%)$ & $6(6.7 \%)$ \\
\hline Breech & $0(0 \%)$ & $2(6.7 \%)$ & $0(0 \%)$ & $2(2.2 \%)$ \\
\hline Twin pregnancy & $1(3.3 \%)$ & $0(0 \%)$ & $4(13.3 \%)$ & $5(5.6 \%)$ \\
\hline
\end{tabular}


There was not a statistically significant difference between WBC levels of the cases at preoperative and postoperative first days, between CRP levels during the preoperative period, between axillary fever values during the preoperative period, between axillary fever levels at postoperative days 1, 3, 5 and 7 , between hospitalization times, and between the incidences of endometritis $(p>0.05)$. Endometritis was observed in none of the cases at postoperative day 1 (Table 3, Figure 1).

\section{Table 3: Evaluation of WBC, CRP, Axillary Fever, Hospitalization time, Endometritis and Wound Infection}

\begin{tabular}{|lcccc|}
\hline WBC Preop & $\begin{array}{c}\text { Single Antibiotics } \\
\text { Use (n:30) } \\
\text { Mean } \pm \text { SD }\end{array}$ & $\begin{array}{c}\text { Multiple Antibiotics } \\
\text { Use (n:30) Mean } \pm \text { SD }\end{array}$ & $\begin{array}{c}\text { No Antibiotics } \\
\text { Use (n:30) } \\
\text { Mean } \pm \text { SD }\end{array}$ & ss \\
\hline WBC Postop Day 1 & $10,504.67 \pm 1,780.60$ & $10,691.00 \pm 2,689.02$ & $10,216.33 \pm 225.79$ & $0.718^{*}$ \\
\hline CRP Preop & $12,978.00 \pm 2,125.08$ & $13,263.33 \pm 381.75$ & $13,552.00 \pm 240.58$ & $0.743^{*}$ \\
\hline CRP Postop Day 1 & $6.79 \pm 3.40$ & $4.53 \pm 1.70$ & $5.94 \pm 2.77$ & $0.094^{*}$ \\
\hline Axillary fever Postop Day 1 & $36.68 \pm 0.39$ & $52.27 \pm 18.95$ & $103.38 \pm 25.83$ & $0.001^{*}$ \\
\hline Axillary fever Postop Day 3 & $36.67 \pm 0.32$ & $36.67 \pm 0.28$ & $36.89 \pm 0.44$ & $0.055^{*}$ \\
\hline Axillary fever Postop Day 5 & $36.76 \pm 0.51$ & $36.66 \pm 0.24$ & $36.84 \pm 0.44$ & $0.076^{*}$ \\
\hline Axillary fever Postop Day 7 & $36.73 \pm 0.45$ & $36.66 \pm .41$ & $36.86 \pm 0.52$ & $0.285^{*}$ \\
\hline Hospitalization time (days) & $3.06 \pm 0.36$ & $36.68 \pm 0.25$ & $36.84 \pm 0.51$ & $0.325^{*}$ \\
\hline Endometritis & $\mathrm{n}(\%)$ & $3.13 \pm 0.51$ & $3.40 \pm 0.81$ & $0.076^{*}$ \\
\hline Endometritis Postop Day 3 & $0(0 \%)$ & $\mathrm{n} \mathrm{( \% )}$ & $\mathrm{n} \mathrm{( \% )}$ & \\
\hline Endometritis Postop Day 5 & $3(10 \%)$ & $0(0 \%)$ & $1(3.3 \%)$ & $0.364^{* *}$ \\
\hline Endometritis Postop Day 7 & $3(10 \%)$ & $0(0 \%)$ & $3(10 \%)$ & $0.200^{* *}$ \\
\hline Wound Infection (WI) & $\mathrm{n}(\%)$ & $0(0 \%)$ & $3(10 \%)$ & $0.200^{* *}$ \\
\hline WI Postop Day 3 & $0(0 \%)$ & $\mathrm{n}(\%)$ & $\mathrm{n}(\%)$ & \\
\hline WI Postop Day 5 & $4(13.3 \%)$ & $0(0 \%)$ & $8(26.7 \%)$ & $0.001^{* *}$ \\
\hline WI Postop Day 7 & $4(13.3 \%)$ & $2(6.7 \%)$ & $14(46.7 \%)$ & $0.001^{* *}$ \\
\hline
\end{tabular}

Oneway ANOVA Test, ${ }^{*}$ Chi-Square Test, $p<0.01$

There was a statistically significant difference between CRP levels of the groups at postoperative day $1(\mathrm{p}<0.01)$. Postoperative day 1 CRP levels of the cases who were not using antibiotics was significantly higher compared to CRP levels of the cases who were using single and multiple antibiotics (p:0.001, $\mathrm{p}<0.01$ ). Postoperative day 1 CRP levels of the cases who were using multiple antibiotics were significantly higher compared to CRP levels of the cases using single antibiotics ( $p: 0.023$, $\mathrm{p}<0.05)$. (Table 3, Figure 1).

The incidence of wound infections in the 
cases who were not using antibiotics at postoperative days 3,5 and 7 was significantly higher than the cases who were using single and multiple antibiotics $(p<0.01)$.

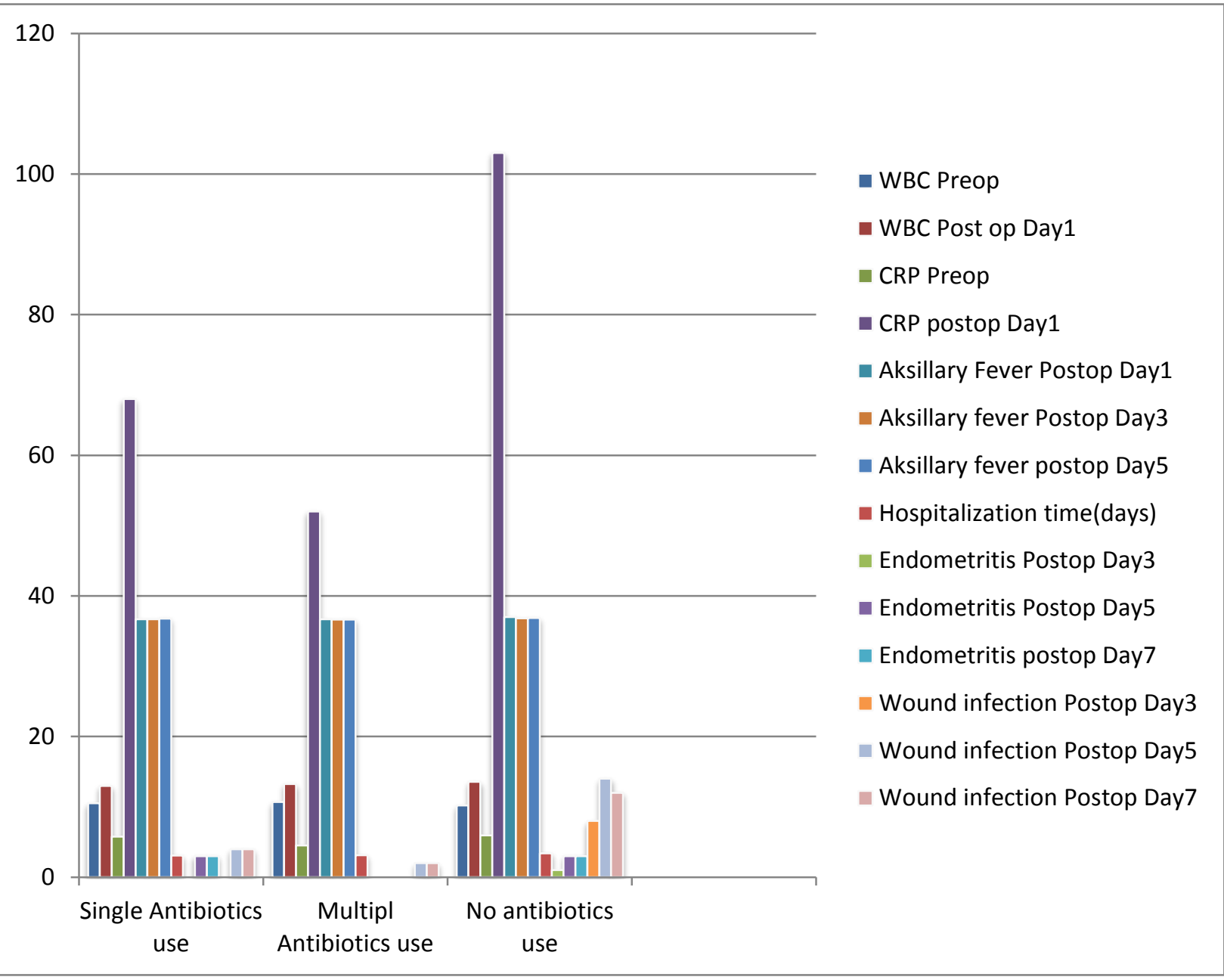

Figure 1: Graphical distribution of WBC, CRP, Axillary Fever, Hospitalization time, Endometritis and Wound Infection

\section{Discussion}

The most significant causes of postoperative morbidity following cesarean delivery are still endometritis and wound infections. ${ }^{17}$ There are various factors that determine infectious morbidity following cesarean delivery. These are operation time, maternal obesity, membrane rupture time, antenatal visits less than seven and not using prophylactic antibiotherapy. ${ }^{18}$
In general, prophylactic antibiotherapy is given before surgical procedures. Antibiotic prophylaxis has eliminated $2 / 3$ of endometritis cases and the majority of wound infections in cesarean cases (elective or non-elective cases). ${ }^{19}$ Burke et al. have first shown that antibiotic use before wound contamination decreased the incidence of wound infections in animal model studies. ${ }^{20}$

In a study by Jakobi et al. evaluating 
prophylactic antibiotic administration, it was found that the use of a single dose of prophylactic antibiotics significantly decreased fever, wound infections, endometritis and urinary system infections compared to the group that was not using prophylactic antibiotics. ${ }^{19}$

In their report evaluating the efficiency of antibiotic regimens and medications in cesarean section, Hopkins et al. reported that administration of prophylactic ampicillin or first generation cephalosporins decreased the risk for postoperative endometritis and administration of wide-spectrum antibiotics or multiple dose antibiotic regimens did not provide an additional benefit compared to ampicillin and first generation cephalosporin administration. ${ }^{21}$ In the study by Alekwe et al., there was no difference in terms of endometritis, wound infections and urinary system infections when a single dose of ceftriaxone was compared with multiple dose combinations of ampicillin, gentamycin and metronidazole for infectious morbidity. ${ }^{22}$

In the study by Smaill et al. comparing administration of prophylactic antibiotics with no prophylaxis administration, it was detected that antibiotic prophylaxis significantly decreased endometritis and it was quite beneficial in preventing wound infections. ${ }^{19}$

In a study comparing the timing of antibiotic prophylaxis, no difference was detected between prophylactic antibiotherapy before skin incision or following cord clamping in terms of infectious morbidity and endometritis. ${ }^{23}$

In the studies evaluating prophylaxis regimens and antibiotics used before cesarean, it was reported that ampicillin and first generation cephalosporins had similar effects in decreasing postoperative endometritis; it was also determined that the addition of multiple dose antibiotic regimens or widespectrum antibiotics to prophylaxis regimens did not have an additional benefit. $^{20}$

In our study, the criteria for wound infections were defined as axillary fever, skin redness, sensitivity, discharge, edema, local temperature increase; endometritis was defined as vaginal temperature increase, tachycardia and the presence of purulent lochia. Laboratory tests of complete blood count and CRP were used to detect infectious morbidity.

Signs of wound infection were only detected in the group which did not undergo antibiotic prophylaxis at postoperative day 3 . The number of cases in this group was $8(26.7 \%)$, the number of cases presenting signs of wound infection at postoperative day 5 was $4(13.3 \%)$ in the group of single dose prophylaxis, $2(6.7 \%)$ in the group of multiple dose prophylaxis and 14 $(46.7 \%)$ in the group who did not undergo prophylaxis; the number of cases presenting signs of wound infection at postoperative day 7 was 4 $(13.3 \%)$ in the group of single dose prophylaxis, $2(6.6 \%)$ in the group of multiple dose prophylaxis and 12 (40\%) in the group who did not undergo prophylaxis. When all groups were compared, signs of wound infection in the group, who had not received prophylactic antibiotics, on postoperative days 3, 4 and 7 was found to be higher than the other groups $(p<0.05)$. No significant difference was detected when single and multiple dose prophylaxis were compared. 
There was not a significant difference between preoperative CRP levels of the groups. When CRP levels on postoperative day 1 were compared, CRP level in the group which did not use antibiotherapy was significantly higher compared to the cases that used single and multiple dose antibiotherapy $(p=0.001)$. Moreover, when cases who underwent single and multiple dose antibiotherapy were compared for CRP at postoperative day 1, CRP level was found to be significantly higher compared to the patients who underwent multiple dose antibiotherapy $(p=0.023)$. There was not a statistically significant difference between axillary fever levels of the groups on postoperative days $1,3,5$ and 7 $(p>0.05)$. There was also no significant difference between groups in terms of hospitalization time.

In general, similar to the literature, wound infections were found to be higher in cases that did not use antibiotics; however, there was no efficiency of dose regimen on infectious morbidity.

When cases of endometritis were evaluated in our study, it was detected in only one case (3.3\%) in the group who did not use prophylaxis on postoperative day 3 . On postoperative days 5 and 7 , endometritis was detected in three cases $(10 \%)$ each in the group of single prophylaxis and in the group who did not undergo prophylaxis. No endometritis was observed in the group of multiple prophylaxis. When the groups were compared, no significant difference was observed in terms of endometritis.

\section{Conclusion}

Wound infection and endometritis are still the most significant causes of postoperative morbidity following cesarean operation. Administration of prophylactic antibiotics is a conventional practice before surgical interventions. In the studies evaluating the efficiency of prophylactic antibiotic administration, it was reported that prophylactic antibiotic administration before the intervention decreased febrile morbidity, wound infection, endometritis and urinary system infection; but there was no difference between single and multiple dose prophylactic antibiotics administration. Also in our study, it was found that prophylactic antibiotics decreased febrile morbidity, wound infection and endometritis; however, there was not a difference between single or multiple dose antibiotic administration.

It is necessary to perform multicentric and randomized controlled studies including increased number of cases in order to achieve more accurate results.

\section{References}

1. Yokoe DS, Christiansen CL, Johnson R, Sands KE, Livingston J, Shtatland ES, Platt R. Epidemiology of and surveillance for postpartum infections. Emerg Infect Dis. 2001 SepOct;7(5):837-41. http://dx.doi.org/10.3201/eid0705.01051 1 PubMed PMID: 11747696. 
2. Ramsey PS, White AM, Guinn DA, Lu GC, Ramin SM, Davies JK, Neely CL, Newby C, Fonseca L, Case AS, Kaslow RA, Kirby RS, Rouse DJ, Hauth JC. Subcutaneous tissue reapproximation, alone or in combination with drain, in obese women undergoing cesarean delivery. Obstet Gynecol. 2005 May;105(5 Pt 1):967-73. http://dx.doi.org/10.1097/01.AOG.00001 58866.68311.d1 PubMed PMID: 15863532.

3. Gibbs RS, Hunt JE, Schwarz RH. A follow-up study on prophylactic antibiotics in cesarean section. Am J Obstet Gynecol. 1973 Oct 1;117(3):41922. PubMed PMID: 4580966.

4. Henderson E, Love EJ. Incidence of hospital-acquired infections associated with caesarean section. J Hosp Infect. 1995 Apr;29(4):245-55. http://dx.doi.org/10.1016/01956701(95)90271-6 PubMed PMID: 7658004 .

5. Leigh DA, Emmanuel FX, Sedgwick J, Dean R. Post-operative urinary tract infection and wound infection in women undergoing caesarean section: a comparison of two study periods in 1985 and 1987. J Hosp Infect. 1990 Feb;15(2):107-16. http://dx.doi.org/10.1016/01956701(90)90119-9 PubMed PMID: 1969432.

6. Boggess $K A$, Watts $D H$, Hillier SL, Krohn MA, Benedetti TJ, Eschenbach DA. Bacteremia shortly after placental separation during cesarean delivery. Obstet Gynecol. 1996 May;87(5 Pt 1):779-84.

http://dx.doi.org/10.1016/0029-

7844(96)00037-3 PubMed PMID: 8677085.

7. Enkin MW, Enkin E, Chalmers I, Hemminki E. Prophylactic antibiotics in association with cesarean section. In: Chalmers I, Enkin MW, Keirse MJNC editors. Effective care in pregnancy and childbirth. Oxford: Oxford University Press; 1989. p. 1246-69.
8. Chelmow D, Ruehli MS, Huang E. Prophylactic use of antibiotics for nonlaboring patients undergoing cesarean delivery with intact membranes: a meta-analysis. Am J Obstet Gynecol. 2001 Mar;184(4):65661.

http://dx.doi.org/10.1067/mob.2001.111 303 PubMed PMID: 11262468.

9. Mahomed K. A double-blind randomized controlled trial on the use of prophylactic antibiotics in patients undergoing elective caesarean section. $\mathrm{Br} \mathrm{J}$ Obstet Gynaecol. 1988 Jul;95(7):689-92. http://dx.doi.org/10.1111/j.14710528.1988.tb06531.x PubMed PMID: 3046651.

10. Noyes N, Berkeley AS, Freedman K, Ledger $W$. Incidence of postpartum endomyometritis following single-dose antibiotic prophylaxis with either ampicillin/sulbactam, cefazolin, or cefotetan in high-risk cesarean section patients. Infect Dis Obstet Gynecol. 1998;6(5):220-3.

http://dx.doi.org/10.1155/S10647449980 00441 PubMed PMID: 9894177.

11. Smaill F, Hofmeyr GJ. Antibiotic prophylaxis for cesarean section. Cochrane Database Syst Rev. 2002;(3):CD000933. Update in: Cochrane Database Syst Rev. 2010;(1):CD000933. PubMed PMID: 12137614.

12. Page CP, Bohnen JM, Fletcher JR, McManus AT, Solomkin JS, Wittmann $\mathrm{DH}$. Antimicrobial prophylaxis for surgical wounds. Guidelines for clinical care. Arch Surg. 1993 Jan;128(1):79-88. Erratum in: Arch Surg 1993 Apr;128(4):410. http://dx.doi.org/10.1001/archsurg.1993. 01420130087014 PubMed PMID: 8418785. 
13. Thigpen BD, Hood WA, Chauhan S, Bufkin L, Bofill J, Magann E, Morrison JC. Timing of prophylactic antibiotic administration in the uninfected laboring gravida: a randomized clinical trial. Am J Obstet Gynecol. 2005 Jun;192(6):18648; discussion 1868-71. http://dx.doi.org/10.1016/i.ajog.2004.12. 063 PubMed PMID: 15970833.

14. Sullivan SA, Smith T, Chang E, Hulsey T, Vandorsten JP, Soper D. Administration of cefazolin prior to skin incision is superior to cefazolin at cord clamping in preventing postcesarean infectious morbidity: a randomized, controlled trial. Am J Obstet Gynecol. 2007 May;196(5):455.e1-5. Erratum in: Am J Obstet Gynecol. 2007 Sep;197(3):333.

http://dx.doi.org/10.1016/.ajog.2007.03. 022 PubMed PMID: 17466699.

15. Fejgin MD, Markov S, Goshen S, Segal J, Arbel Y, Lang R. Antibiotic for cesarean section: the case for 'true' prophylaxis. Int J Gynaecol Obstet. 1993 Dec;43(3):257-61. http://dx.doi.org/10.1016/00207292(93)90513-V PubMed PMID: 7907035 .

16. Wax JR, Hersey K, Philput C, Wright MS, Nichols KV, Eggleston MK, Smith JF. Single dose cefazolin prophylaxis for postcesarean infections: before vs. after cord clamping. J Matern Fetal Med. 1997 Jan-Feb;6(1):61-5. http://dx.doi.org/10.1002/(SICl)15206661(199701/02)6:1<61::AIDMFM13>3.0.CO;2-P PubMed PMID: 9029389.

17. Rasmussen SA, Maltau JM. [Complications following cesarean section]. Tidsskr Nor Laegeforen. 1990 Jan 30;110(3):351-3. Norwegian. PubMed PMID: 2309178.
18. Killian CA, Graffunder EM, Vinciguerra TJ, Venezia RA. Risk factors for surgical-site infections following cesarean section. Infect Control Hosp Epidemiol. $2001 \quad$ Oct;22(10):613-7. http://dx.doi.org/10.1086/501831 PubMed PMID: 11776346.

19. Smaill FM, Gyte GM. Antibiotic prophylaxis versus no prophylaxis for preventing infection after cesarean section. Cochrane Database Syst Rev. 2010 Jan 20;(1):CD007482. http://dx.doi.org/10.1002/14651858.CD0 07482.pub2 Update in: Cochrane Database Syst Rev. 2014;10:CD007482. PubMed PMID: 20091635 .

20. Burke JF. The effective period of preventive antibiotic action in experimental incisions and dermal lesions. Surgery. 1961 Jul;50:161-8. PubMed PMID: 16722001.

21. Hopkins L, Smaill FM. Antibiotic prophylaxis regimens and drugs for cesarean section. Cochrane Database Syst Rev. 2012 Jan 18;1:CD001136. doi: 10.1002/14651858.CD001136.pub2. PubMed PMID: 22258944.

22. Alekwe LO, Kuti O, Orji EO, Ogunniyi SO. Comparison of ceftriaxone versus triple drug regimen in the prevention of cesarean section infectious morbidities. J Matern Fetal Neonatal Med. 2008 Sep;21(9):638-42. http://dx.doi.org/10.1080/147670508022 20490 PubMed PMID: 18828055.

23. Yildirim G, Gungorduk K, Guven HZ, Aslan $\mathrm{H}$, Celikkol $\mathrm{O}$, Sudolmus $\mathrm{S}$, Ceylan Y. When should we perform prophylactic antibiotics in elective cesarean cases? Arch Gynecol Obstet. 2009 Jul;280(1):13-8. http://dx.doi.org/10.1007/s00404-0080845-7 Epub 2008 Nov 26. PubMed PMID: 19034470. 